\title{
Article \\ Determination of the LNG Bunkering Optimization Method for Ports Based on Geometric Aggregation Score Calculation
}

\author{
Yong-Ung Yu ${ }^{1}$, Young-Joong Ahn ${ }^{2}$ a and Jong-Kwan Kim ${ }^{2, *(1)}$ \\ 1 College of Maritime Sciences, Korea Maritime \& Ocean University, Busan 49112, Korea; yyung@kmou.ac.kr \\ 2 Korea Institute of Maritime and Fisheries Technology, 367, Haeyang-ro, Yeongdo-gu, Busan 49111, Korea; \\ yjahn@seaman.or.kr \\ * Correspondence: jkkim@seaman.or.kr; Tel.: +82-51-620-5794; Fax: +82-51-620-5853
}

check for updates

Citation: Yu, Y.-U.; Ahn, Y.-J.;

Kim, J.-K. Determination of the LNG Bunkering Optimization Method for Ports Based on Geometric

Aggregation Score Calculation. J. Mar.

Sci. Eng. 2021, 9, 1116. https://

doi.org/10.3390/jmse9101116

Academic Editor: Mihalis Golias

Received: 7 September 2021

Accepted: 9 October 2021

Published: 14 October 2021

Publisher's Note: MDPI stays neutral with regard to jurisdictional claims in published maps and institutional affiliations.

Copyright: (c) 2021 by the authors. Licensee MDPI, Basel, Switzerland. This article is an open access article distributed under the terms and conditions of the Creative Commons Attribution (CC BY) license (https:// creativecommons.org/licenses/by/ $4.0 /)$.

\begin{abstract}
Owing to stricter environmental regulations of the International Maritime Organization (IMO) 2020, the demand of liquefied natural gas (LNG) bunkering is expected to grow by approximately 15\% during 2020-2025 along with increased investments in eco-friendly ships by global shipping companies. Thus, determining optimal methods for LNG bunkering using existing ports that lack LNG bunkering infrastructure is necessary. Here, a method is proposed to determine the optimal LNG bunkering method for existing ports. Analyzing previous studies, we selected four evaluation factors: assessment of LNG supply for ships, suitability of fuel supply, risk of spillage, and domestic and international standards, which were used to calculate a geometric aggregation score via normalization, weight, and aggregation for selecting an appropriate LNG bunkering method. The analytical results indicated that the ship to ship (STS) method, evaluated based on the size and type of ships, is optimal for the Busan port. This is expected to contribute to the competitiveness of ports and their safety and economic feasibility by serving as a basis for determining the optimal LNG bunkering implemented in existing ports. It is necessary to expand the follow-up research to improve the evaluation method by aggregating more improved data through real cases.
\end{abstract}

Keywords: LNG bunkering; optimization method; geometric aggregation score calculation

\section{Introduction}

The discussion on the International Maritime Organization (IMO) 2020 environmental regulation began in earnest when the international convention for the prevention of pollution from ships (MARPOL) protocol of 1997 was adopted. The protocol was adopted because of the increase in the pollutants-sulfur oxides and nitrogen oxides-released from ships and entered into force on 1 January 2020 [1]. The international community and shipping companies have been employing strategies to reduce greenhouse gas (GHG) emissions from ships by more than $50 \%$ in 2050 relative to the emissions in 2008 with the environmental, social, and governance (ESG) strategy of corporations. Global shipping companies are obligated to reduce GHG emissions by at least $40 \%$ compared with the 2008 level by 2030 and by at least $70 \%$ by 2050 through gradual improvements to carbon intensity using the energy efficiency design index for new ships based on the IMO 2050 carbonneutral policy [2]. Thus, international classification societies (ABS, DNV, LR, etc.) that belong to the International Association of Classification Societies have been recommending alternatives to global shipping companies in response to GHG emission regulations. These recommendations include the optimization of logistics and transportation, change of ship fuel oil, improvement in energy efficiency, and slow steaming. The classification societies emphasize the switching from marine fuel oil to LNG as a practical alternative fuel for ships based on short- and mid-term perspectives [3]. Global shipping companies have started adjusting the priorities of applicable alternatives in the order of ultra-low sulfur fuel oil, marine gas oil, new installation of a scrubber, and LNG-fueled ships as the price difference between high- and low-sulfur fuel oils decreased in 2020 [4]. Therefore, the market for 
LNG bunkering is expected to grow at a compound annual growth rate of approximately $15 \%$ during the period of 2020-2025 [5]. Accordingly, global shipping companies are placing more orders for new LNG-fueled ships while building related infrastructures [6].

The LNG bunkering model will encounter increasing demand for LNG bunkering as the model not only improves the port operation efficiency but also considerably affects port facility investments. Therefore, the aim of this study is to propose an LNG bunkering optimization model for ports by using a geometric aggregation score. The factors that should be considered in a port management information system (Port-MIS) to develop the optimization model were identified based on natural language processing and relation extraction using the R Studio program. Further, research questions related to the key issues were derived. Based on these issues, the priorities of evaluation elements were defined to apply an LNG bunkering optimization model in the existing ports; the characteristics of each port, cargo, and ship type were reflected by analyzing priorities and weights. Through this process, the quantified evaluation methods were developed for evaluating the LNG fuel supply for ships required by existing port facilities, the suitability of LNG fuel supply for ships according to the characteristics of each port facility, risks from LNG leakage during the supply of LNG fuel for ships, and relevant domestic and international standards. An overview of this study is shown in Figure 1.

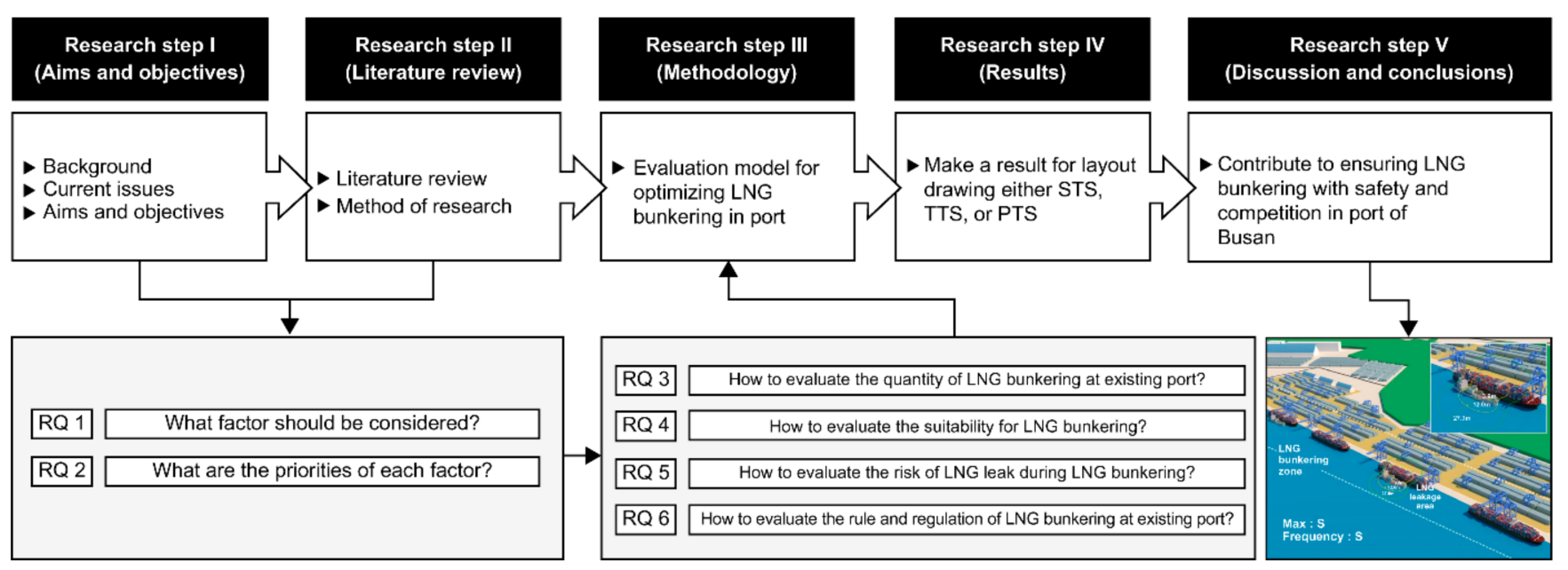

Figure 1. Step-by-step methodology for identifying the optimal LNG bunkering scenario for Busan Port.

This study focused on the Sinseondae Pier in Busan North Port, which is classified as a representative existing port in Busan Port and is the largest port in South Korea. Sinseondae Pier was selected because it is suitable for evaluating existing ports as it has the oldest port facilities in Busan Port; moreover, the port allows the examination of various ship sizes because large ships can dock in the pier. Thus, we developed an LNG bunkering optimization model considering the target pier-Sinseondae Pier-and suggested the development of a customized layout. The following research questions were answered:

1. Research Question No. 1: What factors should be considered when developing an LNG bunkering optimization model using existing port facilities?

2. Research Question No. 2: Is it necessary to apply and review priorities for each factor to develop an LNG bunkering optimization model considering the characteristics of each port?

3. Research Question No. 3: How to evaluate the quantity of LNG bunkering for ships required in existing port facilities among factors used for the development of an LNG bunkering optimization model considering the characteristics of each port.

4. Research Question No. 4: How to evaluate the suitability of LNG bunkering according to the characteristics of the existing port facilities to develop an LNG bunkering optimization model considering the characteristics of each port. 
5. Research Question No. 5: How to evaluate the risk of LNG leakage during LNG bunkering in existing port facilities to develop an LNG bunkering optimization model considering the characteristics of each port.

6. Research Question No. 6: How to evaluate the rules and regulations of LNG bunkering in existing facilities to develop an LNG bunkering optimization model considering the characteristics of each port.

In Section 2, previous related studies are summarized, existing studies are reviewed, and approaches in this study are described. In Section 3, the factors to be considered to develop the LNG fuel supply evaluation model are categorized into four (bunkering conception: LNG fuel requirement, facility characteristics, hazard analysis, and bunkering regulation), and each detailed element is defined. To prioritize each element, they were quantitatively identified based on a analytic hierarchy process (AHP) through a survey of a group of 16 experts from seven institutions (port authority, shipping companies, seafarers, academy, class, agency, and pilots), and the facility characteristics of an existing port as detailed elements among categories were analyzed through an expert survey based on the accessibility and installation possibility of LNG bunkering facilities. For the hazard analysis, the explosion hazard safety distance was established based on the LNG concentration according to the distance based on the risk of LNG leakage, and the hazardous facilities and risk levels in the existing port were indexed. In addition, the bunkering regulation was divided into international standards (such as IMO and Oil Companies International Marine Forum (OCIMF)) and Korea's domestic standards. Then, indexing was performed by considering whether LNG bunkering based on the regulation was applied in consideration of the characteristics. In Section 4, this indexed factor is presented to evaluate the suitability of each bunkering method. This is performed by using geometric aggregation score calculation for the case of performing LNG bunkering by berthing a vessel passing through an existing port facility at any given time. The suggested layout of floor plan for optimal LNG bunkering is also described. In this study, we identified factors determining the LNG bunkering model and proposed an evaluation method to determine the optimal model. This evaluation method will help not only LNG suppliers, shipping companies, and port operators to determine the optimal model but also policy makers, consultants, and port designers in planning port development.

\section{Literature Review}

We intend to develop a port LNG bunkering optimization evaluation model using a geometric aggregation score. The score is calculated based on theories related to prioritization according to expert evaluation results. We also aim to maximize the effectiveness of the optimization model by schematizing evaluation results according to the priorities of each port. To this end, several previous studies have provided insight into the development of LNG bunkering operation procedures, risk assessment, and technology utilization.

Lindstad [7] reported how LNG can serve as a transition fuel in the decarbonization of maritime transport while ensuring the lowest possible additional global warming effect. The transition considers the process of moving away from existing fuels toward new, lowsulfur carbon fuels and main engine technologies. Serra and Gianfranco [8] presented a critical overview of the main measures and initiatives that can be adopted by the maritime industry to cope with the new requirements of the IMO. The pros and cons of the emission reduction options are analyzed along with the main challenges and barriers to its implementation and potential facilitators that can help foster a wider application. Vaferi et al. [6] suggested an analytical model for converting heavy fuel oil to an LNG dual-fuel marine engine in a fleet with three types of vessels to investigate the effect of volatility of oil prices and the declining energy return on investment when adopting LNG as a reliable fuel. From these studies, it is expected that the need for LNG bunkering will increase as LNG is used as a fuel for ships.

$\mathrm{Wu}$ and Lin [9] evaluated the cost-benefit analysis method in terms of the feasibility and implementation benefits of these strategies, that is, the use of very low-sulfur fuel 
oil and scrubber for stricter environmental regulations. A container ship serving the shipping route was selected as a representative example. Hüffmeier and Johanson [2] discovered that achieving energy efficiency through behavioral changes requires not only understanding and empathy with user interests and needs but also the fostering of energysaving awareness, in addition to a technique and framework that supports operators and ship owners. Lee et al. [10] reported that the derived priority of the optimal LNG bunkering method of the shipyard was of the order of STS, TTS (Truck to Ship) and PTS (Pipe to Ship) thorough AHP techniques. Monios et al. [11] researched a method for quantifying the port development potential through comparative analysis, cluster analysis, and a combination of various methods. Zadeh et al. [12] defined similarity relations in fuzzy theory and noted that the fuzzy order is a generalization of the concept of order. The fuzzy theory is used in deriving evaluation factors in various ports and evaluating them accordingly. Gao et al. [13] evaluated the potential of Quanzhou port through the fuzzy theory, AHP, and ELECTRE III (elimination and choice translation reality) methods in three aspects: government policy, investment trends, and investment risk management. Wan et al. [14] considered a quantitative evaluation model for the growth of a transit port using the AHP and D-S reasoning methods. PAWSA (Ports and Waterways Safety Assessment) [15] —an AHP-based matrix-score-based evaluation model—was established, and a quantitative evaluation of each port, water facility, and port facility in the United States was conducted for the quantitative evaluation of the USCG (United States Coast Guard) port risk. Mou et al. [16] classified various factors for the quantitative evaluation of the port potential in the Yangtze River Delta and evaluated various ports using the FAHP (Fuzzy Analytical Hierarchy Process) entropy model. Moreira et al. [17] emphasized that index-based approaches are widely employed for measuring flood vulnerability; however, uncertainties in index construction are rarely considered. Surisa et al. [18] presented a general overview of selected aggression instruments and assisted in identifying instruments that may be best-suited. Mazziotta and Pareto [19] focused on the problem of summarizing a set of socio-economic indicators and aimed to provide general guidelines for constructing a composite index. Chen et al. [20] presented two minutes-max models to optimize the point estimates of the weights. Park and Park [21] suggested a method for estimating the size of the LNG fuel infrastructure required for measuring the status of ports according to the estimated amount of LNG bunkering demand in the future with a case study of the Busan Port. In these studies, the quantitative evaluation of port facilities including LNG bunkering was conducted, and the AHP method was mainly used for this evaluation. Although this evaluation is suitable for subdividing and evaluating each index, calculating a comprehensive score for adequacy evaluation is problematic.

In particular, when using LNG as a fuel, it is essential to evaluate the risk. Thus, we review studies conducted on the risks through various methods. Lee et al. [22] focused on LNG fuel boil-off gas (BOG) management because it is more difficult than normal BOG management; dynamic simulations were conducted using Aspen HYSYS (Aspen Technology, Inc., Bedford, MA, USA), a chemical process simulator used to mathematically model chemical processes. Vidmar et al. [23] provided a risk assessment framework for incorporating collisions between sailing and moored ships. Sys et al. [24] investigated the most important bunker choice determinants: price per ton, quality of fuel, or other characteristics. Ung et al. [25] comprehensively compared LNG bunkering regulation systems in China and Japan and addressed how Korea can mirror these systems to improve the Korean system. Roh et al. [26] analyzed gas leakage from valves through ANSYS flow simulation (Ansys company, Canonsburg, PA, USA), a commercial software with pre and post-processing functions that support finite element analysis, to analyze the gas and pressure distribution inside the fuel cell system. Wei and Zhang et al. [27] analyzed the filling process for the sloshing condition of a liquid storage tank simulated numerically by ANSYS Fluent 17.0. Park and An [28] conducted the financial practicability of the proper terminal capacity using each berth of the automatic container terminal from the perspective of a terminal operating company. 
However, as can be observed from the previous studies, studies related to the determining the optimal model of LNG bunkering have hardly been conducted. Therefore, it is necessary to determine and evaluate a comprehensive evaluation method by considering various risk factors of LNG bunkering.

\section{Methodology and Calculation}

\subsection{Keyword Analysis}

For the LNG bunkering infrastructure, we studied 115 papers (e.g., journal publications and related reports) published since 2010, via web crawling for 10 days from 23 March 2021. The main keywords were analyzed using text mining with the R Studio program (version: R-4.0.5) [29]. Table 1 shows the classification of 115 data (articles, reports, papers, etc.) web-crawled for keyword analysis.

Table 1. Classification of web-crawled keywords.

\begin{tabular}{cccc}
\hline Type & Terms (Years) & Region & Amount \\
\hline \multirow{3}{*}{ Journal article } & $2012 \sim 2020$ & European & 42 \\
& & East Asia & 44 \\
& & Middle Asia & 2 \\
News paper & $2016 \sim 2021$ & North America & 6 \\
& & European & 6 \\
Reports & East Asia & 2 \\
& $2013 \sim 2020$ & North America & 3 \\
\hline
\end{tabular}

$\mathrm{R}$ is a programming language and software environment for statistical calculations and graphics. R-Studio implements various statistical and graphic techniques such as linear and non-linear modeling, classical statistical testing, time-series analysis, classification, clustering, and text mining. The keyword analysis results indicate that between rankings 1 and 20, the most frequently used word stems were "ship", "fuel", "emission", "gas", "operation", "use", "study", "vessel", "bunker", "port", "natural", "regulation", "environment", "energy", "increase", "reduction", "policy", "gross", "marine", and "global" in the descending order of frequency. The keywords were tokenized through stemming after removing stopwords such as meaningless words or investigations through data preprocessing to extract keywords presented as the most important issues. The key elements required for an LNG bunkering optimization model of the target port in this study were derived, as summarized in Table 2, through an analysis of the above keywords. Therefore, an LNG bunkering optimization model that can quantify them comprehensively based on the correlations of these key elements is required.

Table 2. Keyword analysis of LNG bunkering.

\begin{tabular}{cccccc}
\hline Index & Keyword & Frequency & Index & Keyword & Frequency \\
\hline 1 & ship & 146 & 11 & natural & 37 \\
2 & fuel & 120 & 12 & regulation & 35 \\
3 & emission & 90 & 13 & environment & 33 \\
4 & gas & 64 & 14 & energy & 32 \\
5 & operation & 47 & 15 & increase & 29 \\
6 & use & 46 & 16 & reduction & 28 \\
7 & study & 43 & 17 & policy & 26 \\
8 & vessel & 42 & 18 & gross & 25 \\
9 & bunker & 42 & 19 & marine & 25 \\
\end{tabular}




\subsection{Methodology}

The summary score used in the fitness evaluation was obtained by synthesizing the measured values of the quality evaluation index. The geometric aggregation score calculation process, where normalization, weight, and aggregation are performed in sequence, is shown in Figure 2.

\section{Process of geometric aggregation score calculation}
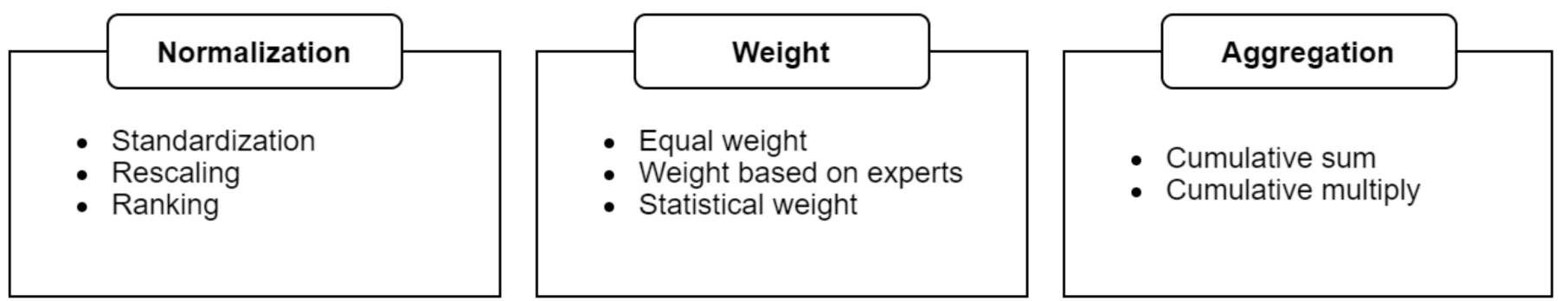

Figure 2. Schematic of cumulative multiplication-type LNG bunkering optimization model.

Normalization-the first step for ensuring the objectivity of the geometric aggregation score calculation result-converts the metrics of different units to the same unit for calculating the aggregate score [20]. The measurements can be objectified in various ways, such as via standardization, rescaling, and ranking of the factors. Each element is standardized on a scale of 0.0-1.0; further, the elements are scaled according to the size of the vessel to apply a uniform scale. To standardize the elements of each bunkering method according to the type of vessel and characteristics of port facilities, AHP was used, targeting a group of 16 experts from seven institutions (port authority, shipping companies, seafarers, academy, class, agency, and pilots) specified as port experts. The level of risk according to LNG fuel was standardized based on the spread of spillage, and the application was classified according to the ranking of related regulations and standardized according to standards. Finally, the ranking was applied to weights as each element.

In the second step, the calculated index is weighed. The weights represent the relative importance of individual indices and can be derived using equal weight, weight based on experts or consumers judgment, or statistical weight. The weights for each element in this study were determined through the AHP results of a group of 16 experts for the evaluation. The final step is aggregation, which aggregates the metric values after normalization and weighting [21]. In this process, cumulative summation or cumulative multiplication can be used. The geometric aggregation score was calculated using the cumulative multiplication method in this study.

Cumulative multiplication is used to calculate the geometric aggregation score for the LNG bunkering optimization model for ports because it can help to quantify the limitations of each bunkering method clearly when relative values need to be used. Further, it is impossible to use absolute values because standards and facility characteristics applied to each type of LNG bunkering are clear. It is necessary to derive the result by clearly quantifying the case wherein the use of LNG bunkering is restricted or prohibited when calculating the cumulative geometric aggregation score because of one factor, although other factors have sufficient optimality in the evaluation of each factor. For example, when LNG bunkering is prohibited by port regulations in a port or terminal during berthing, there is an independent and absolute influencing factor that cannot satisfy the requirement for a large quantity of LNG bunkering by the truck to ship method [28]. Here, the cumulative multiplication theory is applied to the LNG bunkering optimization model for ports.

The geometric aggregation score calculation method must be selected carefully considering the object of evaluation for each factor because there can be differences in the selection of the method and the quality level of the evaluated organization in aggregate score calculation. A representative algorithm for selecting the optimal aggregate score 
calculation method was proposed by [22]. The geometric aggregation score calculation based on this algorithm requires quantification considering individual factors for the selection of a theoretical framework, selection of more representative indicators, treatment for comparison, and cumulative aggregation.

Therefore, this study attempts to solve the problem pointed out by prior research considering the characteristics of each factor of "port", "port cargo", "cargo", "cargo ship", "ship", and "LNG bunkering" by providing (1) a clear definition of the aggregate score, (2) a selection of indices, (3) a normalization of indices, and (4) an aggregation of the normalized indices. Although there are no generalized rules about the weight, normalization, and aggregation, which need to be selected in the process of geometric aggregation score calculation, indexing is performed considering relative/absolute and subjective/objective weights according to the type of each factor. Further, as shown in Figure 2, the measurements of the evaluation indices are quantified through the cumulative multiplication-type aggregate score for an LNG bunkering optimization using existing ports; the indexing results in the form of single values are indicated on the floor plan as an alternative.

\subsection{Geometric Aggregation Score Calculation}

The LNG bunkering optimization model to be applied to existing port facilities is classified into four types based on the $\mathrm{R}$ analysis data and prior research. Among them, Bc (Bunkering Conception: LNG Fuel Requirement) - an evaluation factor based on the bunkering quantity required for the vessel to sail—was evaluated by subdividing the size of the vessel and the characteristics of each type of vessel. A quantitative evaluation was performed for three bunkering methods. Among the three bunkering methods evaluated, the first method is Ship to Ship (STS), which supplies fuel through double banking with a vessel receiving fuel and a shuttle vessel for fuel supply. The second is Truck to Ship (TTS), which supplies fuel to ships through a tank lorry, and the third is Pipe to Ship (PTS), in which pipes are installed at facilities such as docks and directly supply fuel to ships from onshore storage facilities. Four evaluation factors of Bc (bunkering conception: LNG fuel requirement), Fc (facility characteristics), $\mathrm{Ha}$ (hazard analysis), and $\mathrm{Br}$ (bunkering regulation) were used for the target port facilities of the bunkering optimization model. The optimal values were calculated in the order of cumulative aggregation.

$$
\left\{\begin{array}{l}
\text { STS } \\
\text { TTS } \\
\text { PTS }
\end{array}\right\} \text { Optimal evaluation }=\mathrm{Bc} \times \mathrm{Fc} \times \mathrm{Ha} \times \mathrm{Br}
$$

A detailed evaluation method for each factor is presented in Figure 3. Three bunkering types currently considered for LNG fuel ships-STS, TTS, and PTS-were selected to evaluate the optimal LNG bunkering method. The four factors were subdivided and selected to select the optimal method for each bunkering method: Bc is subdivided into the size and type of vessel based on gross tonnage; Fc is subdivided into piers and berths, which are the anchorage facilities of the vessel; $\mathrm{Ha}$ is the risk based on the spread of spillage during LNG bunkering; and $\mathrm{Br}$ is bunkering. The related regulations are applied. Then, a model was established to select the optimal bunkering method through the cumulative aggregation method (Equation (1)) for rating each evaluation factor. 


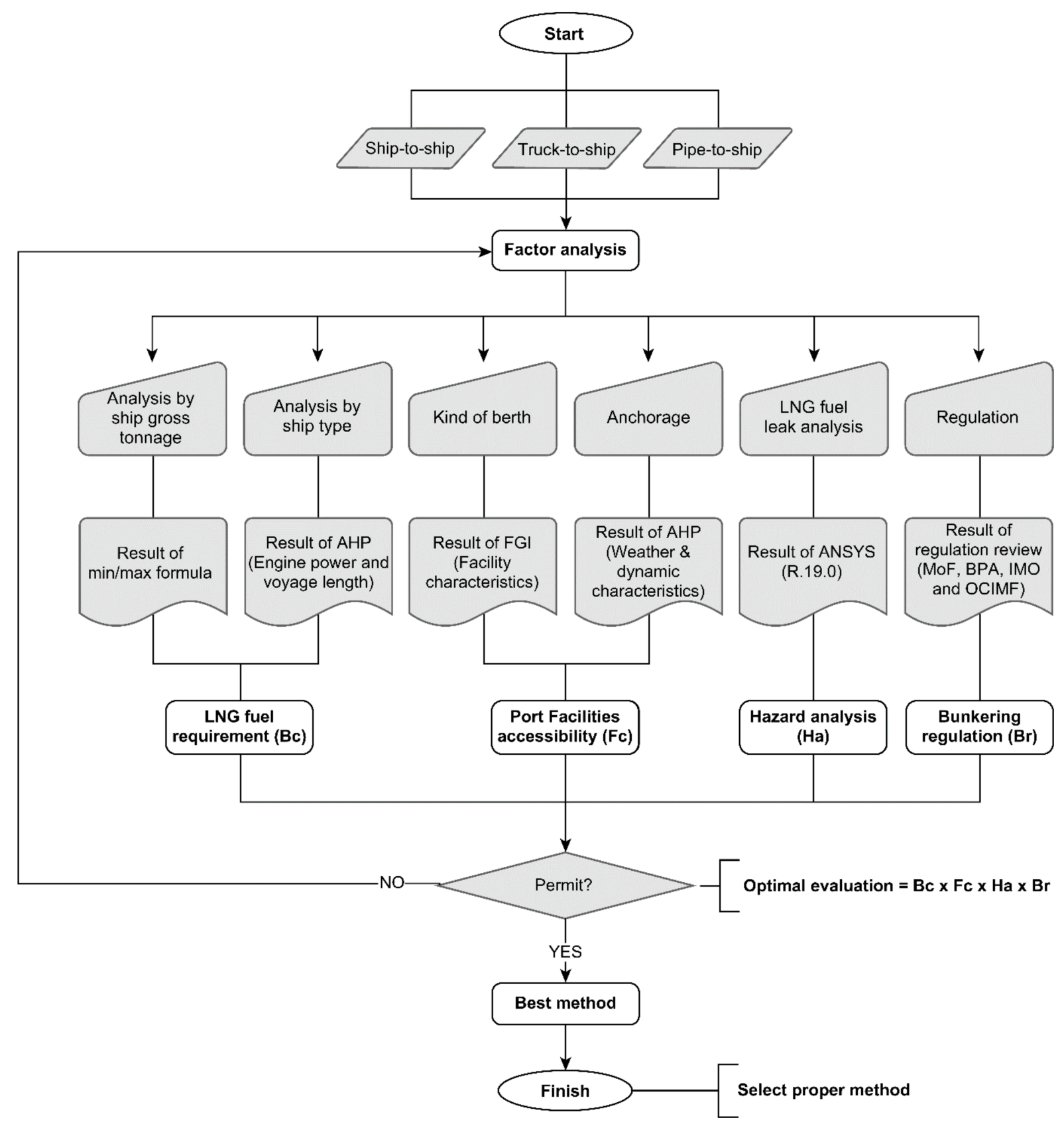

Figure 3. Flowchart representing LNG bunkering at the Busan Port.

\subsection{Definition of and Calculation Method for Each Factor}

Assuming that LNG bunkering is performed for all ships in existing port facilities, we derived an optimal bunkering method by applying the LNG bunkering optimization model for each port facility. Busan Port handles the largest volume among ports in South Korea. The Busan North Port was the largest container port in South Korea until the opening of Busan New Port, and it has the oldest port facilities among operational ports in South Korea [23]. In the Busan North Port, Sinseondae Pier is the largest pier that can accommodate the largest vessels and volume. Therefore, it was selected as the target pier because it is expected to have the largest demand for LNG bunkering in the Busan North Port in the future.

The detailed factor results of each evaluation factor calculated and applied to the Busan Port Sinseondae Pier in this study are as follows. 
$\mathrm{Bc}$ is defined as the required quantity of LNG bunkering based on the size and type of vessel that berths at the target port facilities. In the case of TTS, the supply quantity of LNG bunkering is limited by truck size. STS requires the minimum quantity for one bunkering as it is a method of bunkering by loading LNG in a ship for LNG bunkering. Hence, the preferred bunkering method depends on the required quantity of LNG bunkering, which depends on the size and type of the target vessel. $\mathrm{BC}$ is divided into a factor according to the size of the target vessel, $\mathrm{Bc}_{g}$ (bunkering consumption by gross tonnage), and a factor according to the vessel type, $\mathrm{Bc}_{T}$ (bunkering consumption by vessel type). Then, it was quantified as

$$
\mathrm{Bc}=\mathrm{Bc}_{g} \times \mathrm{Bc}_{T}
$$

In this study, $B c_{g}$ was quantified by using the Min-Max equation for the size based on the gross tonnage of the vessel according to the minimum and maximum bunkering quantities by the bunkering type. $\mathrm{Bc}_{g}$ is given as

$$
\begin{gathered}
\mathrm{Bc}_{g}=0<\frac{x_{a}-\min }{\max -\min }<1, \\
\text { if } \mathrm{Bc}_{g}>1 \text { or } \mathrm{Bc}_{g}<0, \mathrm{Bc}_{g} \text { is regarded as } 0
\end{gathered}
$$

where $x_{a}$, max and min represent gross tonnage of the target vessel, maximum possible supply by bunkering method, and minimum required supply by bunkering method, respectively. Min and Max were calculated based on the minimum required supply quantity per supply and the maximum possible supply for each bunkering method, respectively [20].

Minimum and maximum values obtained by the bunkering method were set in accordance with the recommendations of the IMO [30]. The IMO recommends 300-500 $\mathrm{m}^{3}$ for the max of TTS and $300 \mathrm{~m}^{3}$ or more for the min of STS. In this study, the target vessels using LNG bunkering included not only the minimum vessels but also the maximum vessels that arrived at and departed from the Busan Port. The max-min values for each bunkering method were set as shown in Table 3. Among the LNG bunkering vessels of $300 \mathrm{~m}^{3}$, which correspond to the min of STS and the max of TTS, the 3000 ton container ship using the Korea-China-Japan route, which can sail by one LNG bunkering, was selected as the minimum vessel. Further, a 250,000 ton container ship, which is the maximum vessel that can enter Busan Port as of 2021, was selected for the maximum to be applied to STS and PTS.

Table 3. Analysis of LNG bunkering calculation of max-min values for each bunkering method.

\begin{tabular}{ccc}
\hline Method & Min & Max \\
\hline STS & 3000 & over 250,000 \\
PTS & 0 & over 250,000 \\
TTS & 0 & 3000 \\
\hline
\end{tabular}

However, among the values quantified using the Min-Max equation, " 0 " was used if it was less than " 0 ". When the result exceeded 1 , it was also evaluated as " 0 " to derive the result of the cumulative multiplication method because it cannot be applied if it exceeds the acceptable limit of the method. For example, when targeting a 5000 ton class vessel in the TTS method, it is evaluated as 1.67 in the min-max formula; when a vessel exceeding the maximum supply for each method is targeted, the result value exceeds 1 . In the case of the 2000 ton ship, the cumulative results are excluded as they are evaluated as less than 0 and less than the minimum scale.

Furthermore, $\mathrm{Bc}_{T}$ represents the characteristic of the vessel type. In the case of vessels of the same size, the maximum fuel consumption per day varies depending on the voyage distance and the speed of the vessel because of the navigation characteristics of the vessel type. The weights were quantified using the AHP method for a group of experts who work in Busan Port based on $C_{D}$ (daily consumption) and $V_{L}$ (voyage distance) to reflect the different characteristics of vessel types. A group of 16 experts who participated in 
the calculation of $\mathrm{Bc}_{T}$ through AHP included the Busan Port Authority (BPA), shipping companies, seafarers, academy, class, the Ministry of Oceans and Fisheries, and pilots. It was calculated in the range of 0 to 1.0 for each method. The results of quantifying $\mathrm{Bc}_{T}$ for Busan Port are summarized in Table 4.

Table 4. Factor rating by vessel type (Busan Port).

\begin{tabular}{ccccccccc}
\hline Method & $\begin{array}{c}\text { Container } \\
\text { Ship }\end{array}$ & Car Carrier & $\begin{array}{c}\text { International } \\
\text { Ferry }\end{array}$ & Tanker & $\begin{array}{c}\text { Bulk } \\
\text { Carrier }\end{array}$ & $\begin{array}{c}\text { General } \\
\text { Cargo Ship }\end{array}$ & $\begin{array}{c}\text { Other Small } \\
\text { Ships }\end{array}$ & $\begin{array}{c}\text { Public } \\
\text { Ships }\end{array}$ \\
\hline STS & 0.80 & 0.70 & 0.65 & 0.90 & 0.80 & 0.50 & 0.10 & 0.10 \\
PTS & 0.05 & 0.05 & 0.05 & 0.10 & 0.05 & 0.20 & 0.40 & 0.30 \\
TTS & 0.15 & 0.25 & 0.30 & 0.00 & 0.15 & 0.30 & 0.50 & 0.60 \\
\hline
\end{tabular}

Facility characteristics $(\mathrm{Fc})$ are factors that depend on the characteristics of port facilities that perform LNG bunkering. Port facilities wherein ships perform bunkering are classified into two types: berthing wharf and anchorage. Wharfs are classified as gravity wharf, open-type wharf, and dolphin. Anchorage is used when a mooring buoy is anchored at sea. Port facilities were classified into four types here; their characteristics are as follows:

1. Gravity wharf: The loading strength is high for the direct loading of cargoes on top of the approaching quay.

2. Open-type wharf: Ships directly berth at the wharf, but the weight on top of the wharf is restricted.

3. Dolphin: Ships directly berth at the wharf, but the approach is limited because the wharf is for oil cargoes.

4. Mooring buoy or anchorage: Ships are berthed or moored at sea.

The Fc factor was quantified based on Ac (accessibility characteristics) and Ip (possibility of installation of bunkering facilities (trucks, pipes, vessels)) in the target port for a group of experts working in Busan Port. A group of 16 experts who participated in the quantification of Fc through AHP included the BPA, shipping companies, seafarers, academy, class, the Ministry of Oceans and Fisheries, and pilots. It was calculated to be 0-1.0 for each method; the quantification results are summarized in Table 5. However, Fc of the dolphin and anchorage (including Buoys) made it impossible to install pipes and access the trucks due to the natural environment.

Table 5. Factor rating by facility characteristics (Busan Port).

\begin{tabular}{ccccc}
\hline Method & Gravity Wharf & Open-Type Wharf & Dolphin & Mooring Buoy or Anchorage \\
\hline STS & 0.55 & 0.60 & 1.00 & 1.00 \\
PTS & 0.10 & 0.05 & 0.00 & 0.00 \\
TTS & 0.45 & 0.35 & 0.00 & 0.00 \\
\hline
\end{tabular}

Ha (hazard analysis) represents the result of evaluating the risks of LNG leaks in surrounding facilities and vessels during bunkering in the target port facilities for each LNG bunkering optimization model. The Korea Marine Equipment Research Institute analyzed the distance of the risk sections based on the possibility of explosion when LNG fuel is leaked during bunkering, using ANSYS Inc. (Pittsburgh, PA, USA) for Busan Port in 2020 [29]. The risky sections according to the LNG leak were distinguished into red, yellow, and green zones based on the probability of explosion; the details are summarized in Table 6.

$\mathrm{Br}$ (bunkering regulation) is quantified by reflecting the restrictions and regulations related to LNG bunkering applied to bunkering in Busan Port. The Port and Fishing Port Design Guidelines of the South Korean Ministry of Oceans and Fisheries (2017) stipulate a separation of $30 \mathrm{~m}$ or more between vessels with dangerous goods and passing vessels (route) [31]. Further, the factor ratings were divided depending on the distance from port facilities, LNG bunkering vessels, or facilities to nearby routes or traffic flow. For handling dangerous goods, bunkering during cargo operations (loading and discharg- 
ing) is prohibited at the wharf handling dangerous goods according to the recommendation of the OCIMF, which presents the standards and recommendations at sea related to handling dangerous goods. Further, the factors related to the wharfs handling dangerous goods and general wharfs are applied differently. The quantification results are summarized in Table 7.

Table 6. Designation of explosion and distance according to LNG leak.

\begin{tabular}{clc}
\hline Concept & Designation & Distance \\
\hline $\begin{array}{c}\text { Upper explosion limit (UEL) (15\% or higher } \\
\text { upper limit of explosion) }\end{array}$ & Red zone $\%$ & $3.1-3.9 \mathrm{~m}$ \\
$\begin{array}{c}\text { Lower explosion limit (LEL) (5\% or higher lower } \\
\text { limit of explosion) } \\
\text { Safe zone of 1\% or lower }\end{array}$ & Yellow zone & $6.8-12.0 \mathrm{~m}$ \\
\hline
\end{tabular}

※ However, double banking of small ships for ship to ship operation was excluded when reviewing LNG bunkering.

Table 7. Factor rating according to regulations related to bunkering.

\begin{tabular}{|c|c|c|c|c|}
\hline \multirow{3}{*}{$\begin{array}{l}\text { LNG bunkering } \\
\text { (STS, PTS, TTS) }\end{array}$} & Classification & Target Standards & Applicatio & f Standards \\
\hline & South Korean standards & $\begin{array}{l}\text { Port and Fishing Port Design Standards } \\
\text { (A distance of } 30 \mathrm{~m} \text { or more between } \\
\text { a vessel handling dangerous goods } \\
\text { such as fuel oil and a passing vessel) }\end{array}$ & $\begin{array}{l}30 \mathrm{~m} \text { or less } \\
\text { between bunkering } \\
\text { facilities (vessels) } \\
\text { and route } \\
0.0\end{array}$ & $\begin{array}{c}\text { More than } 30 \mathrm{~m} \\
\text { between bunkering } \\
\text { facilities (vessels) } \\
\text { and route } \\
1.0\end{array}$ \\
\hline & OCIMF & $\begin{array}{l}\text { It is prohibited to supply ship fuel oil } \\
\text { while handling dangerous goods (it can be } \\
\text { supplied after completing the cargo work) }\end{array}$ & $\begin{array}{l}\text { Wharf handling } \\
\text { dangerous goods } \\
0.5\end{array}$ & $\begin{array}{c}\text { Other cargos than } \\
\text { dangerous goods } \\
1.0\end{array}$ \\
\hline
\end{tabular}

\section{Results}

\subsection{Result of Geometric Aggregation Score Calculation}

The evaluation results of the Sinseondae Pier in Busan North Port were quantified for each factor based on the evaluation method. First, the number and size of ships berthing at the target wharf were investigated based on the Port-MIS data to evaluate the optimality of the LNG bunkering method of the target wharf [32]. The details of the maximum ship (Max ship) and ship with the largest frequency of berths (LFB Ship) at the target wharf are systematized for the time period from January 2020-December 2020 in Table 8. Thus, an assessment based on the size and type of ship summarized in Table 8 was performed here.

Table 8. Target vessel's details for optimality evaluation.

\begin{tabular}{ccc}
\hline Classification & Max Ship & LFB Ship \\
\hline Gross tonnage & 66,452 & 3997 \\
\hline Ship type & \multicolumn{3}{c}{ Container Ship } \\
\hline
\end{tabular}

The results of quantifying $\mathrm{Bc}_{g}$ using Equation (3) based on the gross tonnage of the target vessels for STS, PTS, and TTS are summarized in Table 9. As discussed in Section 3, 0 was applied to the factor rating for the Min-Max equation (Equation (3)) below 0; this indicates a short supply, and for the result exceeding 100, it indicates an excess supply.

Table 9. Risk assessment according to STS, PTS, and TTS methods.

\begin{tabular}{ccc}
\hline Method & Max Ship & LFB Ship \\
\hline STS & 0.2569 & 0.0040 \\
PTS & 0.2658 & 0.0160 \\
TTS & 0.0000 & 0.0000 \\
\hline
\end{tabular}


For $\mathrm{Bc}_{T}$, both the Max ships and the LFB ship among the ships entering the Sinseondae Pier were both container ships. Therefore, 0.80 was applied for STS, 0.05 for PTS, and 0.15 for TTS as the factor rating.

For Fc, the Sinseondae Pier in Busan Port has the form of an open-type wharf. Therefore, 0.60 was applied for STS, 0.05 for PTS, and 0.35 for TTS as the factor rating.

For $\mathrm{Ha}$, the value of green (1.0) was applied for factor rating because there was no risk factor around the bunkering point.

For the STS method in Br, the LNG bunkering ships were separated from the route by more than $30 \mathrm{~m}$, even during double banking. In the PTS and TTS methods, there were no facilities for dangerous goods within $30 \mathrm{~m}$ of the target bunkering ships. Furthermore, OCIMF was not applicable because the wharf did not handle dangerous goods. Therefore, a value of 1.0 was applied for factor rating because there were no bunkering restrictions in domestic and international regulations.

For the weight of each evaluation factor, the factor ranking was determined in terms of priority using AHP based on the evaluation of the expert group of Busan Port. Priorities differed according to the LNG bunkering method, as listed in Table 10. As a result of calculating the weight by a factor, high weights were selected for the size of the ship, the structural characteristics of the wharf, and risk assessment results in STS and TTS, whereas high weights were determined for the vessel type and bunkering regulation factors in PTS.

Table 10. Expert priorities for each optimization factor of LNG bunkering in Busan Port.

\begin{tabular}{ccccccc}
\hline \multirow{2}{*}{ Method } & \multicolumn{2}{c}{$\mathbf{B c}$} & $\mathbf{F c}$ & $\mathbf{H a}$ & $\mathbf{B r}$ & \multirow{2}{*}{ Sum } \\
\cline { 2 - 6 } & $\mathbf{1 . 0 - 5 . 0}$ & $\mathbf{1 . 0 - 5 . 0}$ & $\mathbf{1 . 0 - 1 0 . 0}$ & $\mathbf{1 . 0 - 1 0 . 0}$ & $\mathbf{1 . 0 - 1 0 . 0}$ & \\
\hline STS & 1.90 & 1.60 & 3.7 & 3.30 & 3.45 & The sum of each factor \\
PTS & 1.30 & 1.90 & 2.8 & 3.25 & 3.40 & was scored within the \\
TTS & 1.80 & 1.50 & 3.5 & 3.45 & 3.15 & range of 10.0. \\
\hline
\end{tabular}

Table 11 summarizes the results of evaluating the optimality for each LNG bunkering method of the Sinseondae Pier reflecting expert priority based on four factors (Bc, Fc, Ha, $\mathrm{Br}$ ) applied in the LNG bunkering optimization model.

Table 11. Evaluation of optimality of each LNG bunkering method for Sinseondae Pier.

\begin{tabular}{|c|c|c|c|c|c|c|c|}
\hline \multicolumn{2}{|c|}{ Method } & $\mathrm{Bc}_{g}$ & $\mathbf{B c}_{T}$ & Fc & На & $\mathrm{Br}$ & Result \\
\hline \multirow{2}{*}{ STS } & Max Ship & 0.4881 & \multirow{2}{*}{1.2800} & \multirow{2}{*}{2.2200} & \multirow{2}{*}{3.3000} & \multirow{2}{*}{3.4500} & 15.7912 \\
\hline & LFB Ship & 0.0076 & & & & & 0.2459 \\
\hline \multirow[b]{2}{*}{ PTS } & Max Ship & 0.3455 & \multirow[b]{2}{*}{0.0950} & \multirow{2}{*}{0.1400} & \multirow{2}{*}{3.2500} & \multirow{2}{*}{3.4000} & 0.0509 \\
\hline & LFB Ship & 0.0208 & & & & & 0.0031 \\
\hline \multirow{2}{*}{ TTS } & Max Ship & 0.0000 & \multirow{2}{*}{0.2250} & \multirow{2}{*}{1.2250} & \multirow{2}{*}{3.400} & \multirow{2}{*}{3.1500} & 0.0000 \\
\hline & LFB Ship & 0.0000 & & & & & 0.0000 \\
\hline
\end{tabular}

The priority of each bunkering method for each ship in the target pier can be determined using Equation (5) based on the optimality result for each bunkering method for the Max ship and the LFB ship at the Sinseondae Pier. As shown in Table 12, the Max ship showed an optimality of approximately $99.7 \%$ for STS and $0.3 \%$ for PTS. Further, the LFB ship showed an optimality of approximately $98.8 \%$ for STS and approximately $1.2 \%$ for PTS. Therefore, in the case of the Sinseondae Pier, STS was found to be the optimal bunkering method.

$$
\text { Priority Bunkering Metoid }(\%)=\frac{\text { Bunkering Type }}{\text { STS }+ \text { PTS }+ \text { TTS }} \times 100
$$


Table 12. Result of optimal priority evaluation for each bunkering method in Sinseondae Pier.

\begin{tabular}{ccccccc}
\hline Evaluation Target Ship & \multicolumn{2}{c}{ STS } & \multicolumn{2}{c}{ PTS } & TTS \\
\hline Max ship & $99.6794 \%$ & 1st & $0.3206 \%$ & 2nd & $0.00 \%$ & Not applicable \\
LFB ship & $98.7720 \%$ & 1 st & $1.2280 \%$ & 2nd & $0.00 \%$ & Not applicable \\
\hline
\end{tabular}

\subsection{Layout in Floor Plan}

The optimal LNG bunkering optimization model of the Sinseondae Pier in Busan Port is roughly indicated using the symbols STS (S), TTS (T), and PTS (P) in the layout shown in Figure 4 . The symbol "S" was marked because STS was ranked first with an optimality of $99.68 \%$ for the Max ship. The LFB ship was also marked as symbol "S" as in the Max ship according to the optimality values of $98.78 \%$ for STS and $1.23 \%$ for PTS. Sinseondae Pier is a pier docked by ships engaged in international voyages beyond Southeast Asia. Thus, TTS, which is suitable for the size of ships engaged in coastal or Korea-China-Japan voyages, cannot be considered as a model for bunkering. In the case of PTS, the priority is limited to $1.23 \%$ because of the vessel type and characteristics of the wharf facilities. Hence, STS was selected as the LNG bunkering optimization model with the highest priority.

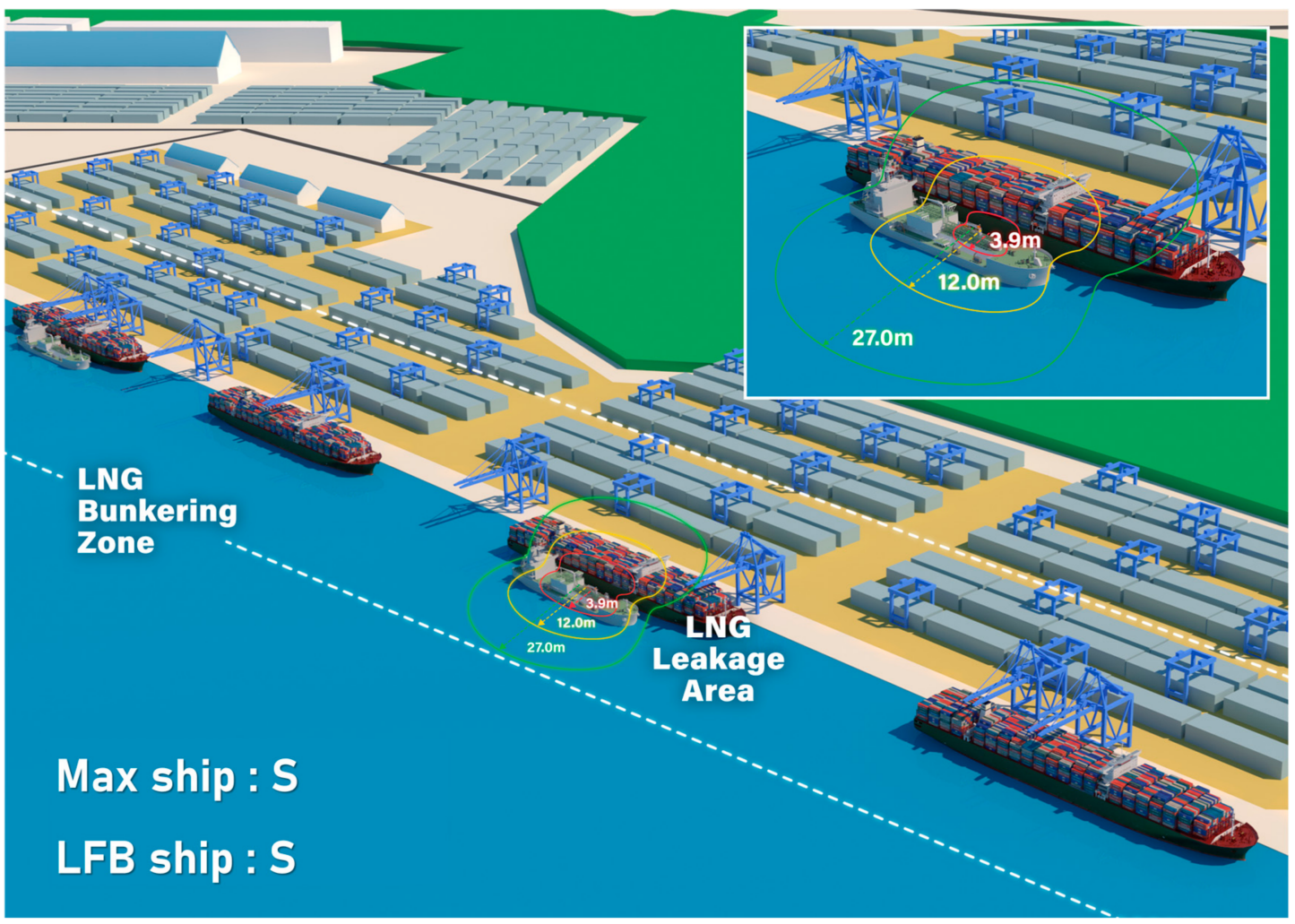

Figure 4. Layout of Busan port (Sinseondae) using the optimal LNG bunkering method.

\section{Discussion}

LNG-fueled ships are expected to increase because of global environmental issues and the importance of LNG bunkering, which is an infrastructure for these ships that will inevitably be emphasized continuously. Consequently, a model for determining the optimal LNG bunkering method needs to be developed, and this model should consider economic aspects and safety.

Previous studies used various port evaluation methods using cost-benefit and fuzzy theory; however, the most representative method among them is the AHP method based on the experience and knowledge of the expert about the object of assessment and scientific theory. Although the AHP method has the advantage of being useful for obtaining weight 
and importance, it still has the disadvantage of difficulty in evaluating complementary factors. However, in the current stage, where there is a lack of demonstration of LNG as a bridge fuel that must be used until carbon neutrality is achieved by 2050, applying weights using the AHP method appears to be a realistic representative alternative.

An LNG bunkering optimization model for ports was developed here using a cumulative multiplication-type method through the process of normalization, weight, and aggregation to improve these limitations and problems substantially. As the evaluation factors of the optimization model, bunkering conception, facility characteristics, hazard analysis, and bunkering regulation were developed and scored using cumulative aggregation.

The STS method showed an optimality higher than $98 \%$ for the Sinseondae Pier in Busan North Port. Furthermore, for the evaluation factors, STS and TTS showed high weights in the vessel size, the structural characteristics of the wharf, and risk assessment results, whereas PTS showed high weights in vessel type and bunkering regulation factors. The largest difference in weight was observed in the structural characteristics. This is attributed to the limitation of PTS regarding the installation of the facilities in the wharf.

The method and results of this study can be used to select the optimal LNG bunkering method that can provide the highest safety and economic feasibility using the existing facilities and environment of ports. It will considerably contribute to economic achievements such as the efficient operation of the port and the stimulation of incidental services.

However, this study has several limitations. Empirical data on various types and sizes of LNG-fueled ships entering and leaving South Korea are still insufficient. Consequently, there is a limitation in that the general data on LNG bunkering ships and trucks in the demonstration stage were taken on a test bed. Hence, even if the optimization model is developed, there is a limitation in the reliability of the demonstration data for each factor applied to the optimization model. Therefore, if LNG bunkering is performed in the future, this study needs to improve the reliability of the data by collecting these data and performing more quantitative standardizations using AHP while providing more concrete information to experts. Ultimately, the limitation of indexing caused by the insufficient practical data will be overcome by accumulating data through the expansion of related vessels in future research. That is, if actual data are accumulated for each factor rather than the data by testbed, a more accurate suitability evaluation can be achieved. Therefore, if these evaluation factors are generated and the evaluation method is improved, the application of the proposed method can be expanded to more areas.

The ISO-type LNG container method, which is being applied in some island countries, has not yet been commercialized, and as such, it is not acknowledged as a representative LNG bunkering technology. Thus, it was excluded in this study, but the method and scope of research will be expanded through follow-up research considering future technological changes.

\section{Conclusions}

This study uncovered evaluation factors for selecting the optimal LNG bunkering method when ships perform LNG bunkering using existing ports without the required infrastructure. Further, an evaluation method based on cumulative aggregation was proposed.

The results of the research questions of this study are as follows.

1. Four factors for developing an optimal LNG fuel supply evaluation model for ships using existing port facilities were selected based on previous research and $\mathrm{R}$ analysis data.

2. The priority of each element was evaluated by the AHP method considering weights.

3. The LNG fuel supply for ships required by the existing port facilities was calculated based on the maximum possible supply and minimum supply required for one supply based on the total tonnage of the ship.

4. The geometric aggregation score calculation model was applied to the suitability of LNG fuel supply for ships according to the characteristics of each existing port facility. 
5. For the risk of LNG leakage during its supply to ships, the distance to the dangerous section was analyzed based on the possibility of explosion using ANSYS.

6. Relevant domestic and international standards that should be applied to existing port facilities were quantified by reflecting restrictions or regulations.

The findings and contributions of this study can be summarized as follows.

1. This study proposed an evaluation method based on cumulative aggregation to determine the optimal LNG bunkering method when implemented in existing ports without the required infrastructure. This method is characterized by finding the optimal bunkering method that can calculate the geometric aggregation score based on the evaluation of the suitability of each evaluation factor.

2. The proposed evaluation method was applied to the Sinseondae Pier in Busan North Port-a representative port in South Korea-and the results showed that the STS method was the optimal method with a score higher than $98 \%$. A large difference in weight occurred among the three bunkering methods in the evaluation factor $\mathrm{Fc}$, and factors with the largest effect in PTS were analyzed as installation facilities according to the port characteristics and accessibility. The newly proposed evaluation method is useful for determining the optimal LNG bunkering method for existing ports. Hence, if the proposed evaluation method is introduced, the risk of potential accidents that can occur during LNG bunkering in an existing port can be reduced; this can contribute to the improvement of safety and economic feasibility. However, the current data are based on test bed-level data rather than actual data. Therefore, follow-up research is required in the future to collect additional data related to LNG bunkering and improve the evaluation factors based on these data. In particular, an evaluation model for situations where various kinds of LNG bunkering are possible, such as anchorage and open sea, must be developed. In addition, if practical data for developing such an evaluation model are supported, various follow-up studies will be possible. If this follow-up research can enhance the reliability of evaluation and generalize the evaluation method, it will considerably contribute to the competitiveness of ports such as LNG bunkering.

In the future, this study will contribute to the provision of basic data to government agencies, port authorities, related companies, research centers, and universities that research the LNG bunkering optimization model by drawing floor plans and schematics based on these evaluation results. These results will be reflected in the LNG bunkering method of existing ports, regulation development, and port operation plan. Furthermore, it contributes to the transformation of shipping companies, port authorities, and logistics companies around the ESG environment by evaluating and improving the safety of the supply of LNG fuels for ships included in the broad concept of ship refueling business. This strengthens the competitiveness of South Korea in the eco-friendly port services while improving the air environment.

Author Contributions: Conceptualization: Y.-U.Y.; methodology: J.-K.K.; validation J.-K.K.; investigation: Y.-U.Y., Y.-J.A. and J.-K.K.; resources: J.-K.K.; data curation: Y.-J.A.; writing-original draft preparation, Y.-U.Y.; writing-review and editing, Y.-J.A.; supervision, J.-K.K.; project administration: Y.-U.Y.; funding acquisition, Y.-U.Y. All authors have read and agreed to the published version of the manuscript.

Funding: This work was supported by a grant from the National R\&D Project, "Development of LNG Bunkering Operation Technologies based on Operation System and Risk Assessment", funded by the Ministry of Oceans and Fisheries, South Korea, grant number PMS4310.

Institutional Review Board Statement: Not applicable.

Informed Consent Statement: Not applicable.

Data Availability Statement: The data presented in this study are available on request from the corresponding author. The data are not publicly available due to restrictions of privacy information on survey. 
Acknowledgments: All the support is gratefully acknowledged. We would like to thank Editage for editing support.

Conflicts of Interest: The authors declare no conflict of interest. The funders had no role in the study design, collection, analyses, or interpretation of data; in the writing of the manuscript; or in the decision to publish the results.

\section{References}

1. IMO. Amendments to the Annex of the Protocol of 1997 to Amend the International Convention for the Prevention of Pollution from Ships, 1973, as Modified by the Protocol of 1978 Relating Thereto. 2016. Available online: https://www.imo.org/en/ OurWork/Environment/Pages/Air-Pollution.aspx (accessed on 4 October 2021).

2. Hüffmeier, J.; Johanson, M. State-of-the-Art Methods to Improve Energy Efficiency of Ships. J. Mar. Sci. Eng. 2021, 9, 447. [CrossRef]

3. DNV-GL, LNG as Ship Fuel 2014. Available online: https://dnv.com/ (accessed on 23 September 2021).

4. Fan, L.; Gu, B. Impacts of the Increasingly Strict Sulfur Limit on Compliance Option Choices: The Case Study of Chinese SECA. Sustainability 2020, 12, 165. [CrossRef]

5. LNG Bunkering Market-Growth, Trends, and Forecast (2020-2025), Mordor Intelligence. Available online: https://www. reportlinker.com/p05865832/LNG-Bunkering-Market-Growth-Trends-and-Forecast.html?utm_source=GNW / (accessed on 20 September 2021).

6. Vaferi, M.; Pazouki, K.; Van Klink, A. Declines in EROI of Main Fuels and the Implications on Developing LNG as a Marine Fuel. J. Mar. Sci. Eng. 2020, 8, 719. [CrossRef]

7. Lindstad, E.; Eskeland, G.S.; Rialland, A.; Valland, A. Decarbonizing maritime transport: The importance of engine technology and regulations for LNG to serve as a transition fuel. Sustainability 2020, 12, 8793. [CrossRef]

8. Serra, P.; Fancello, G. Towards the IMO's GHG goals: A critical overview of the perspectives and challenges of the main options for decarbonizing international shipping. Sustainability 2020, 12, 3220. [CrossRef]

9. Wu, P.C.; Lin, C.Y. Cost-benefit evaluation on promising strategies in compliance with low sulfur policy of IMO. J. Mar. Sci. Eng. 2021, 9, 3. [CrossRef]

10. Lee, Y.G.; Kim, J.K.; Lee, C.H. Analytic hierarchy process analysis for industrial application of LNG bunkering: A comparison of Japan and South Korea. Energies 2021, 14, 2965. [CrossRef]

11. Monios, J.; Wang, Y. Spatial and institutional characteristics of inland port development in China. GeoJournal 2013, 78, 897-913. [CrossRef]

12. Zadeh, L.A. Similarity relations and fuzzy orderings. Inf. Sci. 1971, 3, 177-200. [CrossRef]

13. Gao, T.; Na, S.; Dang, X.; Zhang, Y. Study of the competitiveness of Quanzhou Port on the belt and road in China based on a Fuzzy-AHP and ELECTRE III model. Sustainability 2018, 10, 1253. [CrossRef]

14. Wan, C.; Zhang, D.; Yan, X.; Yang, Z. A novel model for the quantitative evaluation of green port development-A case study of major ports in China. Transport. Res. D 2017, 61, 431-433. [CrossRef]

15. Ports and Waterways Safety Assessment of United States Coast Guard. Available online: https://www.dco.uscg.mil/PAWSA/ (accessed on 7 June 2021).

16. Mou, N.; Wang, C.; Yang, T.; Zhang, L. Evaluation of development potential of ports in the Yangtze river delta using FAHP-entropy model. Sustainability 2020, 12, 493. [CrossRef]

17. Moreira, L.L.; de Brito, M.M.; Kobiyama, M. Effects of different normalization, aggregation, and classification methods on the construction of flood vulnerability indexes. Water 2021, 13, 98. [CrossRef]

18. Suris, A.; Lind, L.; Emmett, G.; Borman, P.D.; Kashner, M.; Barratt, E.S. Measures of aggressive behavior: Overview of clinical and research instruments. Aggress. Violent Behav. 2004, 9, 165-227. [CrossRef]

19. Mazziotta, M.; Pareto, A. Methods for constructing composite indices: One for all or all for one. Ital. Rev. Econ. Demogr. Stat. 2013, 67, 67-80.

20. Chen, M.; Wan, Z.; Chen, X. New min-max approach to optimal choice of the weights in multi-criteria group decision-making problems. Appl. Sci. 2015, 5, 998-1015. [CrossRef]

21. Park, N.K.; Park, S.K. A study on the estimation of facilities in LNG bunkering terminal by simulation-Busan Port case. J. Mar. Sci. Eng. 2019, 7, 354. [CrossRef]

22. Lee, H.; Choi, J.; Jung, I.; Lee, S.; Yoon, S.; Ryu, B.; Kang, H. Effect of parameters on vapor generation in ship-to-ship liquefied natural gas bunkering. Appl. Sci. 2020, 10, 6861. [CrossRef]

23. Vidmar, P.; Perkovič, M.; Gucma, L.; Łazuga, K. Risk assessment of moored and passing ships. Appl. Sci. 2020, 10, 6825. [CrossRef]

24. Aronietis, R.; Sys, C.; Van Hassel, E.; Vanelslander, T. Investigating the bunkering choice determinants: The case of the port of Antwerp. J. Ship. Trade 2017, 2, 1-13. [CrossRef]

25. Yong Ung, Y.; Sung Ho, P.; Dong Ho, J.; Chang Hee, L. Improving liquefied natural gas bunkering in Korea through the Chinese and Japanese experiences. Sustainability 2020, 12, 9585. [CrossRef]

26. Roh, G.; Na, Y.; Park, J.Y.; Kim, H. Analysis of internal gas leaks in an MCFC system package for an LNG-fueled ship. Appl. Sci. 2019, 9, 2330. [CrossRef] 
27. Wei, G.; Zhang, J. Numerical study of the filling process of a liquid hydrogen storage tank under different sloshing conditions. Processes 2020, 8, 1020. [CrossRef]

28. Park, N.K.; An, Y. Financial analysis of automated container terminal capacity from the perspective of terminal operating company. J. Mar. Sci. Eng. 2020, 8, 954. [CrossRef]

29. Kwon, Y.J.; Ban, H.J.; Jun, J.K.; Kim, H.S. Topic Modeling and Sentiment Analysis of Online Review for Airlines. Information 2021, 12, 78. [CrossRef]

30. International Maritime Organization. Studies on the Feasibility and Use of LNG as a Fuel for Shipping; IMO: London, UK, 2016; pp. 44-48.

31. Ministry of Oceans and Fisheries: Port and Fishing Port Design Guideline KDS 6455 10: 2017 General Design of Mooring Facilities. 2017. Available online: http:// kpcs.portcals.go.kr/kc/mv_list.do?doc_Gubun=KDS (accessed on 7 June 2021).

32. Port Management Information System of the South Korean Ministry of Oceans and Fisheries. Available online: https://new. portmis.go.kr/portmis/websquare/websquare.jsp?w2xPath=/portmis/w2/main/intro.xml (accessed on 7 June 2021). 